\title{
MELOT, M. (2015). UMA BREVE HISTÓRIA DA IMAGEM. Vila Nova de Famalicão: Ed. CECS \& Húmus
}

\author{
Zara Pinto-Coelho
}

Nascido a 9 de Agosto de 1943, em Blois, Michel Melot, bibliotecário e historiador de arte, foi Diretor do Departamento de Estampas e Fotografias da Biblioteca Nacional de França (de 1981-1983), onde organizou várias exposições, entre as quais, a grande exposição dedicada à estampa impressionista; Diretor da Biblioteca Pública de Informação do Centro Pompidou (de 1983 a 1990) e Presidente do Conselho Superior das Bibliotecas, no Ministério da Cultura francês, onde dirigiu o inventário geral da arquitetura e do património, tarefa que desenvolveu até à sua reforma (de 1997 a 2003).

É autor de uma vasta obra em arqueologia e história de arte, romances, reflexões sobre o livro, as bibliotecas e o património. Entre as suas obras, destacamos: nos anos 70, (1975) L'CFil qui rit: Le pouvoir comique des images, Paris: Bibliothèque dês arts, (1978) Fontevrault, Paris: CLT; nos anos 80, (1981) L'estampe, Genève: Skira, (1984), L'illustration, Historie d'un art. Genève: Skira; nos anos 90, (1994) L'estampe impressionniste, Paris: Flammarion; nos anos 2000, (2004), La sagesse du bibliothécaire, Paris: l'C $E$ il Neuf, (2006), Livre, Paris: l'CFil Neuf, (2012), Essai sur l'inventaire général du patrimoine culturel. Paris: Gallimard.

Esta vasta bibliografia mostra-nos que Uma Breve História da Imagem é uma das várias obras de Michel Melot dedicada à imagem, uma paixão acompanhada pelo seu interesse pela escrita, a escrita não enquanto fenómeno linguístico, mas enquanto matéria gráfica que se desenrola no espaço.

Neste pequeno livro, originalmente publicado em 2007 pelas edições de L'Oeil Neuf, agora traduzido por Aníbal Alves e publicado pelo Centro de Estudos de Comunicação e Sociedade, em parceria com a editora Húmus, Melot propõe uma breve história da imagem. Organizei esta viagem em várias notas onde registei algumas das impressões e reflexões suscitadas por esta breve história.

\section{DA FALTA QUE AS IMAGENS NOS FAZEM}

Ao longo de nove capítulos, e em apenas 130 páginas, o autor percorre a história da imagem desde os desenhos pré-históricos às imagens numéricas. Transporta-nos no tempo e no espaço, em ziguezague, ora situando-nos nas Grutas Chauvet, em Combe d'Arc, Ardéche, ora na Galáxia de Gutenberg, ora no mundo dos GPs, ora no Ocidente, na China, no Egipto, na Índia, no Afeganistão, ora no Islão, no Cristianismo ou no Calvinismo.

Mas nunca nos dá a ver as imagens que vai referindo ao longo da escrita. Uma opção justificada pelos custos que tal implicaria? Ou será que Melot não quis subordinar as 
imagens à lógica da escrita? Não sabemos. Certo é que as imagens fazem falta aos leitores e o autor parece reconhecer isso. No final do livro, num momento em que apresenta uma bibliografia comentada, escreve: "em matéria de imagens, não basta frequentar livros (...) este livro deve muito à visita de museus" (p. 104). É isso, para o acompanharmos, lado a lado, na viagem que nos propõe, são necessárias muitas imagens, imagens na nossa memória e na nossa experiência e imagens das memórias coletivas. Para quando uma edição multimédia desta Breve História da Imagem?

\section{A PAIXÃo QUe A IMAGEM DESPERTA}

Melot conta esta breve história da imagem de uma forma apaixonada, dialogante, que nos seduz e nos mantêm, simultaneamente, numa permanente posição de tensão e de exigência. Seduz-nos, porque escreve de uma forma clara, escorreita e muitas vezes profundamente poética - há que reconhecer na criação desses efeitos, claro, o engenho e a arte do tradutor, Aníbal Alves. Mas o seu canto de sereia não nos intoxica, não nos abandona à tentação. Mantêm-nos numa posição de atenção permanente: porque nos dá muita informação - é uma história breve, mas espessa, profundamente documentada -, porque dialoga connosco, - pondo em jogo as nossas crenças, aquilo que damos como certo no que à imagem diz respeito - e porque nos desafia a refletir sobre as relações que temos com as imagens, enquanto atores sociais, enquanto humanos e enquanto corpo.

\section{O TEMPO DE VIDA DAS IMAGENS}

O exercício que Melot desenvolve, olhando para a história das imagens da frente para trás, e de trás para a frente, permite-nos compreender a coexistência de dimensões distintas do tempo da imagem: como há passado no presente, não apenas como um "antes" e um "depois", mas como um "durante" que a habita de várias maneiras. São vários os exemplos que Melot nos dá:

- Como ainda hoje se mantêm as práticas mágicas da imagem;

- Como ainda hoje opomos a imagem à escrita, esquecendo que uma imagem é sempre uma escrita, e que uma escrita é primeiramente uma imagem;

- Como a imagem e a escrita partilham os nossos ecrãs, na televisão no telemóvel, tal como acontecia nas paredes paleolíticas;

- Como os pictogramas das escritas figuradas usadas na América até ao século XIX, para contar as façanhas guerreiras de tribos índias, povoam as nossas ruas e os nossos anúncios publicitários, sob a forma de logótipos, tabuletas e painéis de sinalização (p. 25).

Melot ensina-nos que na história da imagem, das suas condições técnicas, dos usos que dela fazemos, e das teorias que sobre ela produzimos, não há propriamente transcendência ou erradicação, mas remediação (Bolter \& Grusin, 1999), dialética e coexistência. A imagem, como artifício humano, salta do seu período para o nosso ou para outros. $O$ 
autor mostra-nos que "a imagem, como a escrita, tem várias histórias" (p. 37), e sublinha que "a origem da imagem não tem de ser procurada no decorrer dos séculos. Ela está sempre em nós. Uma forma torna-se imagem desde que é observada, fazendo logo surgir associações de memórias (p. 23)". Talvez por isso mesmo Melot defenda que a "história da imagem se pode resumir a um eterno combate ou tensão permanente entre analogia e código, ou índice e símbolo, abstração e figuração, realismo e idealismo (p. 25)".

\section{Do MUITO QUE A IMAGEM SOFREU E DO MUITO QUE ELA CONQUISTOU}

Após ter assinalado um giro ou "viragem pictórica" - expressão cunhada por Mitchell (1992), Professor de Inglês e de História de Arte da Universidade de Chicago - que muitos consideram fundamental na história da imagem na cultura judaico-cristã, em que a imagem passou de objeto ligado aos cultos e aos rituais para o uso mundano, dessacralizado, Melot, salienta o seguinte:

- Como com a invenção do pequeno quadro ela mudou de mão, passando do poder espiritual para o poder temporal;

- Como a sua reprodução massiva levantou o problema da originalidade, do seu laço com o original, com o modelo: terá perdido a aura (de que nos fala Benjamin (1992/1936-1939)?

- Como ela sofreu com a invenção do livro impresso: foi "arrastada com as bagagens da escrita" ( $p$. 51), abastardada na forma de ilustração e colocada "fora do texto, ou "fora do jogo", posição marginal em que ficou durante pelos menos três séculos" (p. 53);

- Como se transformou "no instrumento-espelho" com a fotografia;

- Como integrou o gesto e a palavra (p. 83), se encontrou com o som e se pulverizou em pixéis, definindo-se assim matematicamente como uma superfície onde cada ponto é determinado pelas suas coordenadas (p. 95).

- Como fez curto-circuito à linguagem: já que a própria escrita, inventada para escapar à imagem, tornou-se uma delas (p. 98).

- E como fez de nós uma imagem de carne: "a tatuagem faz de nós uma imagem de carne (p. 99), tornando-se corpo.

\section{HistóRIA DE UMA IMAgEM ANUNCIADA}

Será que todos estes progressos são novos, ou completamente novos? Será que há verdadeiras ruturas?

Será que, como defendem alguns -, por exemplo, Moisés Martins no texto "O que podem as imagens?" publicado no livro Imagem e Pensamento, em 2011, pela Grácio Editor - que a proliferação das imagens nos ecrãs significa que a natureza da imagem mudou, que ela já não reenvia ao mundo, nem ao outro, mas que, pelo contrário, são as coisas e somos nós que passamos a imitar as imagens (p. 132)? Ou será que, na verdade, como defende Melot, a natureza da imagem não mudou, a digitalização não levou a imagem a perder a sua natureza analógica - apenas a técnica de reprodução foi digitalizada - e que a relação entre as coisas, nós e as imagens nunca teve, de facto, um sentido único (p. 94)? 
Esta propensão da imagem a integrar-se no real, ou do real a emancipar-se em imagem, não é um facto novo, avisa Melot (p. 99). E diz mais: "nunca os mitos da imagem foram tão fortes como na hora em que julgamos ter dominado as suas técnicas". "Após tanto progresso, como chegamos aí, ou melhor, como "ficamos aí"? (p. 94), pergunta o autor. E conclui: "se há crise de representação, ela é tão velha como a imagem (p. 99).

\section{SOMOS NÓS QUE VEMOS AS IMAGENS OU SERÃO ELAS QUE NOS VÊEM?}

“O verdadeiro perigo está em nós não querermos saber que elas são apenas imagens - é que na verdade as imagens não caem do céu" (p. 35), enfatiza Melot. Importa, por isso, "tirar-lhes o poder feiticeiro que lhes concedemos" (p. 36). E como é que lhes retiramos esse poder?

Descrevendo o que cremos ver nelas? Não, responde Melot, retiramos-lhe esse poder "subindo a corrente dos sentidos que lhe foram dados e deduzindo deles os que nós lhe damos (p. 19).

Decifrando-as, como se fossem jogos de palavras? Não, escreve Melot, devemos antes compreender o que elas escondem, através daquilo que ela mostram (p. 35), uma vez que "toda a imagem é simultaneamente acesso a uma realidade ausente, que simbolicamente evoca, e obstáculo a essa realidade" (p. 14).

Será, então, "que o sentido trazido a uma imagem permanece perpetuamente em aberto? (p. 25). E será que isso significa dizer que as imagens não são codificadas? Então, o que faz com que sejamos capazes de reconhecer como imagem a imagem?

\section{NóS E AS IMAGENS, UMA PAIXÃO SEM LIMITES}

Michel Melot convida-nos a ver as imagens não como coisas, mas como relações. Nos anos sessenta, Guy Débord já o tinha afirmado: "o espectáculo não é um conjunto de imagens, mas uma relação social entre pessoas, mediatizada por imagens" (1967, tese 4).

Ver as imagens como relações, significa, portanto, que as enquadramos, que procuramos a sua razão de ser nas diversas comunidades de produtores e de consumidores de imagens e nas relações entre os mesmos. Significa também compreender que o tempo de vida das imagens está nas mãos dos visionadores. São eles os feiticeiros, e não as imagens em si mesmas. Como bem sublinha Aníbal Alves na nota do tradutor, entender as imagens como relações é entender que elas são sempre de alguma coisa, de que são imagem (p. 6), não devendo, por isso, ser confundidas com a realidade, nem serem vistas como mera ilusão.

Se nos incomodam as imagens que vemos na TV ou nos jornais porquê é que ao invés de nos indignarmos com a realidade social e humana que elas representam, as queremos proibir? Só aqueles que acreditam em fantasmas têm medo das suas imagens, lembra-nos Melot.

É verdade "que a imagem não se aprende como uma língua e escapa à palmatória dos professores, "que ela é sentida antes de ser compreendida" (p. 67), mas livros como 
este ajudam a tornar visível a nossa visão, que é em si invisível; ajudam a torná-la estranha e a precisar de ser explicada, para que se multipliquem os olhares, porque o olhar não é apenas, como se diz usualmente, uma "janela do mundo", mas é também "um espelho da alma" (Jay, 1994, p. 10).

A breve história da imagem que esta obra nos propõe é, de facto, densa e espessa, um verdadeiro exercício crítico e reflexivo que nos desafia a sermos exigentes nas nossas relações com as imagens. Recomendamos a sua leitura a todos quantos as amam.

\section{REFERÊNCIAS BIBLIOGRÁFICAS}

Benjamin, W. (1936-1939/1992). A obra de arte na era da sua reprodutibilidade técnica. In W. Benjamin, Sobre Arte, Técnica, Linguagem e Política (pp. 71-110). Lisboa: Relógio d`Água.

Bolter, J. D. \& Grusin, R. (1999). Remediation. Understanding new media. Cambridge: MIT Press.

Débord, G. (1967). La societé du spectacle. Paris: Buchet Chastel.

Jay, M. (1994). Downcast eyes: The denigration of vision in the twentieth-century French thought. Berkeley: University of California Press.

Martins, M. L. (2011 ). O que podem as imagens. Trajecto do uno ao múltiplo. In M. de L. Martins, J. B. de Miranda, M. Oliveira \& J. Godinho (Eds.), Imagem e Pensamento (pp. 129-135). Coimbra: Grácio Editor.

Mitchell, W. J. (1992). The pictorial turn. Artforum, 89-94.

\section{NOTA BIOGRÁFICA}

Zara Pinto Coelho é Professora Associada do Departamento de Ciências da Comunicação da Universidade do Minho, onde ensina sociologia da comunicação, estudos do discurso e semiótica social. Os seus interesses de investigação incluem as teorias do discurso e as suas aplicações críticas aos estudos dos média e aos estudos culturais, em tópicos relacionados com poder e ideologia, por exemplo, em discursos de participação pública, na cobertura jornalística da saúde ou na interseção do género com a heterossexualidade.

E-mail: zara@ics.uminho.pt

Centro de Estudos de Comunicação e Sociedade, Instituto de Ciências Sociais, Campus de Gualtar, 4710-057 Braga, Portugal

\section{Submetido: 15/03/2017}

Aceite: 16/04/2017 